\title{
The Future of Guidance And Counselling In The 21st Century In Nigeria: Changing Face-To-Face Counselling Through Cyberspace Counselling
}

\author{
Kamilu Olanrewaju Muraina1, Saleh Musa G², Zahrau Muhammad Kabir² \\ ${ }^{1}$ Al-Hikmah University Ilorin, Nigeria \\ 2 Yobe State University, Nigeria
}

\begin{abstract}
The use of technological know-how in all spheres of life has delivered about full-size modifications worldwide. The use of the web has, in some situations, changing face-to-face counseling in the Western World. The future is being formed with the aid of cutting-edge and rising applied sciences that are substantially altering the methods in which humans interact. Such adjustments are the end result of improvement in the fields of Science and Technology. Consequently, our online world counseling is at the forefront of the paradigm modifications that are shaping the future of face-to-face counseling. This paper displays the manageable advantages of our online world counseling in the twenty-first century, its implications, challenges, and possibilities for counselors and the counsellees in Nigeria. Building upon this, the paper additionally concludes that applied sciences can trade the typical face-to-face counseling to our online world counseling thereby lowering the stress on each counselor and consumer in the realm of counseling.
\end{abstract}

Keywords: Cyberspace, Counselling, Face-to-face and Technology

This is an open access article under the CC-BY-NC license.

\section{INTRODUCTION}

The use of the web in the counselling provider has been a welcome improvement in Nigeria. Cyberspace counselling is the provision of expert intellectual fitness counselling providers thru the use of internet. It is additionally regarded as web counselling, e-counselling, online counselling, internet remedy or far flung therapy; this provider is generally presented by way of E-mail, real-time chat, and video conferencing (Lannap, 2012). Cook and Doyle (2002) describe net use, specifically records Communication Technology in counselling practice, as new technological know-how that provides rapid and low-priced options to extraordinary problems. Some counsellees are the use of videoconferencing, stay chat, and E-mail with expert psychologists in the location of or in addition to face-to-face meetings.

In addition, there is a developing fashion of on line recuperation coaches who can now behavior face-to-face consultations with purchasers online. But the query right here is, how then do we domesticate innovative minds that can stand up to the challenges of the online world counselling in the 21st century in creating nations like Nigeria? Reacting to this, Augar, Raitman, and Zhou (2004) remarked that innovative minds are the merchandise of innovative studying, which entails an active, structured strategy that depends on the utility of obtained knowledge, getting to know of methods, and the enterprise of ideas. 
Oliver and Goerke (2007) word that creativity mixed with media recognition and technical competencies are necessary for the success and employment of future generations. Thus, this paper seeks to talk comprehensively and appreciably the future of counselling carriers in the twenty-first century in Nigeria: altering standard face-to-face counseling carrier thru our online world counselling.

\section{An Overview of Counselling Service}

Counselling is an issue of guidance, which many human beings have distinctive views about (Lannap, 2012). According to Oladele (2007), counselling has been used to denote extensive vary of strategies, which include recommendation giving, assistance in instances of hassle or need, encouragement, data giving, and check interpretation. Counselling is a manner by means of capacity of which the helper expresses care and subject toward the man or woman with a problem; it helps that person's non-public increase and brings adjustments thru self-knowledge (Salawu \&amp; Abdulkadir, 2011).

Counselling is a relationship between an involved individual and a man or woman with need. This relationship is commonly man or woman to person, though every so often it might also contain greater than two people. It is designed to assist human beings to apprehend and make clear their views and examine how to reach their self-determined dreams via meaningful, well-informed options and via the decision of emotional or interpersonal problems.

In counselling, customer emotions/feelings are of serious concern. In this regard, Brown (2008) located that twenty-first-century college students get hold of their ideas, stories, facts, and leisure now not solely from books and different printed varieties of media, however additionally from television, films, digital video disks (DVDs) and an increasing number of from the web and cell devices. These consequent name for the use of our online world counseling in a cutting-edge society like ours.

\section{Potentials Benefits of Cyberspace Counselling Services in the Twenty First Century}

Given the viable advantages of applied sciences in the twenty-first century, there is a clear opportunity that the vogue of science and science will proceed to enhance the mode of preparation transport over the subsequent decades, and will embody non-public and cellular devices. Conversely, in growing countries, Oliver and Goerke's (2007) observations published that younger humans are excessive customers of mounted technologies, such as computers, the internet, email, and cellular phones. This is in line with the statement made via Thomas and Knezek (2008: 81) that the present-day college students are described as "digital natives" who have "spent their whole lives surrounded by way of and the usage of computers, videogames, digital song players, video cams, cellphone phones, and all the toys and equipment of the digital age".

Although there is some preliminary help for the opportunity that our online world counseling might also assist consumers who in any other case underutilize usual face-to-face or in-office counselling, the query of the effectiveness and appropriateness of our online world counselling has no longer been resolved yet. Online counselling is additionally filling the unmet want for customers placed in areas traditionally under-served via standard counsellors. Rural residents and expatriates alongside with under-served minorities, frequently have a less difficult time discovering an appropriate therapist online than in their neighborhood communities.

Online counselling has additionally been proven to be fine for customers who may also have situation achieving appointments throughout ordinary working hours. Additionally, lookup suggests that online counselling might also be beneficial for disabled and rural human beings who historically under- 
utilize face-to-face counselling services. In summary, our online world counselling can be of gain in the following ways:

\section{Effectiveness}

Research by means of Stofle (2001) suggests that online counselling would gain humans functioning at a reasonably excessive stage of training and technological savviness. Suler (2000) suggests that human beings functioning at a especially excessive degree of societal advancement, and who are well-educated and are artistically inclined, can also gain the most from the usage of text-based net counselling as a complement to ongoing psychotherapy. Difficult situations, such as suicidal ideation or a psychotic episode, would possibly be higher served with the aid of standard face-to-face methods, even though a similar lookup might also show otherwise. Cohen and Kerr (1998) carried out a find out about the effectiveness of online versus face-to-face remedy for the therapy of nervousness problems in college students and determined that there was once no distinction in the stage of alternate for the two modes as measured via the State-Trait Anxiety Inventory. As the principal intention of counselling is to alleviate the distress, anxiousness, or issues skilled with the aid of a customer when he or she enters therapy, online counselling seems to have robust efficacy below that definition. However, it is vital to observe that customer pleasure surveys have a tendency to show the excessive stage of customer pleasure with on line counselling, whereas the companies every now and then reveal decrease delight with distance methods. Cyberspace counselling is speedy, turning into a famous mannequin for a guide for younger people, with key country wide offerings such as Lifeline, Kids Helpline, Suicide Call Back Service, and headspace including our online world counselling to their provider provision.

\section{Convenience}

Online remedy is convenient. Both the counsellor and the consumer have the comfort of corresponding with every different at varied of variant times. This fashion of remedy can take away the problem of scheduling and placing appointments greater frequently in normal settings. This additionally creates a probability for the therapist to prolong their offerings to extra consumers as appointments can be doubtlessly scheduled over 24 hours and attain a large geographical region. For these men and women who are ambivalent about remedies or who may additionally be uncomfortable with standard fashions of therapy, our online world counselling can also be greater suitable. Indeed, it has been observed that online remedy is desired by way of these who are uncomfortable with face-to-face with any person about their issues or who are struggling from social phobias, agoraphobia or anxiousness problems (Adewuyi and Muraina, 2019; Suleiman, Muraina \&amp; Suleiman, 2019).

\section{Affordability}

Cyberspace counselling has been proven to be extra, not pricey for each the counsellor and the client, mainly for these counsellors who are unwilling or can't come up with the money for to lease industrial house thereby reducing overhead fees of capital, property, commuting and administration methods when in contrast to standard counselling services.

\section{Social stigma}

Cyberspace counselling may also additionally be nice in disposing of social stigma related to receiving therapy. For those who are uncomfortable with receiving therapy, our online world counselling lets in get admission to to such offerings in personal except having to go to the counselling centre. 
Counselling can take on a whole specific photograph when acquired via the consumer in their very own domestic via the computer. It may additionally enable the purchaser to sense much less stigmatized barring having to be considered in the ready room, both by means of the administrative group of workers or any different individual who simply takes place to be strolling previous at the time the customer walks via the door. Because of this, our online world counselling certainly does provide the consumer a diploma of anonymity that may additionally decrease such social stigma and consequently instantaneous them to are looking for help when they may in any other case have hesitated.

\section{Anonymity}

The absence of face-to-face contact can additionally instantaneous customers to speak greater overtly, barring issues for bias of race, gender, age, dimension or bodily appearance. This may additionally lead to an accelerated stage of honesty and consequently, greater validity in the case of selfdisclosure. The net, in reality, affords a degree of anonymity that is perceived by many customers as nonthreatening via permitting an 'invisibility' that can be disinhibiting.

\section{Variant approaches to communicate}

Most verbal exchange thru the net is in written form. Cyberspace counselling, in which the mode of conversation is frequently thru writing by way of emails or a chat room, lets in both the customer and the counsellor to pay shut interest to their verbal exchange and mirror on their ideas and emotions prior to it being expressed. This may additionally be a mainly appropriate way of conversation for these customers who journey concern in expressing themselves in words. Clients may additionally be in a position to talk higher in these surroundings as they are no longer affected via the counsellor's nonverbal cues. Research suggests that writing at some stage in instances of misery is especially beneficial for customers as it is viewed to grant an integral avenue for emotional recovery (Adewuyi and Muraina, 2019). Given that our online world counselling is an interactive structure of therapeutic writing, interventions delivered in these surroundings may additionally be pretty tremendous in encouraging purchasers to be categorical themselves in greater thoughtful, self-reflective, and insightful ways. Having a written report additionally lets the customer have a reference factor in future discussion, evaluation, and in the evaluation of trade and progress.

\section{The implication of Cyberspace Counselling Service Tools for the twenty-first Century}

While on the one hand, the advantages of our online world counselling have been considered, our online world counselling has additionally been criticized in phrases of its lack of verbal and nonverbal cues, difficulties in keeping confidentiality and security, standard effectiveness, technological difficulties and in its limits of being capable to assurance the counsellors' credibility. Some of the implications include:

\section{Absence of verbal and nonverbal cues}

While some benefits of our online world counselling have been introduced above, there are additional hazards in no longer having verbal and nonverbal cues when counselling. Verbal and nonverbal interactions are viewed as quintessential for gauging what the purchaser is feeling and for figuring out the discrepancies or incongruences between verbal and nonverbal behaviours. Cyberspace counselling has been criticized for missing such vital factors of the micro capabilities of counselling. Traditional counselling depends closely on the traits of each verbal and nonverbal cues as a shape of verbal exchange and as a way of gaining perception into the thoughts, emotions, and behaviors round the purchasers supplying concerns. E-therapy does no 
longer provide an indication of characteristics such as voice tone, facial expression, physique language, and eye contact. This can doubtlessly have an impact negatively on the counselling consequences as the counsellor has little chance to take a look at and interpret such cues on the stay video.

\section{Confidentiality and security}

Mental fitness practitioners have a moral duty to defend and hold the confidentiality of their clients. With online remedy, the protection of the client's information and data may want to be jeopardized, and confidentiality is at larger danger of being inappropriately breached given the written nature of the medium. Although most web sites try to have protection structures to defend confidentiality, it is as suitable as the ultra-modern model of the safety software program used. Practitioners will have to continually improve their science to forestall safety breaches.

\section{Effectiveness}

Professionals and laypeople alike have constantly puzzled about the effectiveness of online therapeutic interventions. There is presently some lookup aiding the lack of effectiveness of counselling that is furnished fully thru such a medium. The lack of face-to-face interplay should amplify the danger of misdiagnosis with the aid of the therapist. Because of this, E-therapy is presently deemed inappropriate for the prognosis of medical problems such as continual despair and psychotic disorders.

\section{Technological difficulties}

It is now not uncommon for computer systems to fail and web connections to falter. For example, folks who are in far-flung areas might also have much less than ideal transmission that drops out often or there is usually the opportunity of servers crashing and community connections faltering. The potential to advantage from e-therapy is additionally partly decided through the client's laptop abilities and knowledge, mainly if the conversation putting entails putting in and studying new software programs and/or hardware. This might also disrupt the session and can doubtlessly be distressing for the client.

\section{Therapist credibility}

The purchaser receiving online remedy has little or no assurance about the skills and credentials of their therapist. This exposes the patron to the exploitation of inexperienced persons pretending to be counsellors.

\section{Ethical issues}

As our online world counselling offerings develop and proceed to obtain momentum in popularity, interest will have to be given to the building of prison and moral codes. Particularly due to the fact the net transcends nation and worldwide borders, there are many criminal and regulatory concerns. For example, is it a felony for a practitioner to furnish chat room offerings to purchasers in a jurisdiction that is backyard their licensed or permitted exercise boundary? If no one is aware of who is treating whom, how is a first-class carrier ensured? If a practitioner does no longer understand the place, a purchaser is, how can they name for assist in the case of an emergency, such as suicidal threats? These are some of the questions that therapists will have to think about earlier than they embark on imparting such services.

\section{Challenges of Cyberspace Counselling in Developing Countries}

Despite the truth that the use of the web is very precise for counsellors, the variety and range of net websites and troubles concerned in the incorporation of the net into counselling quantity to some challenges (Mallen \&amp; Day, 2005; Suleiman et al., 2019). Despite the possibilities for the use of technological know-how in a variety of areas of lives, there are manageable challenges worried that may 
deter its profitable implementation and well-timed adoption with the aid of many growing international locations like Nigeria. Topical problems encompass availability of power, net connectivity and bandwidth, best of counsellors' training, and the sustainability of implementations.

Wright (2014) highlighted that electrical strength is crucial to run technological units, and till electricity is extensively available, reliable, and cheap for many in Africa and elsewhere, our online world counselling uptake will be slow. In addition, lack of accessible, dependable, and low-cost net through all and sundry is a top-notch undertaking for e-counseling in twenty-first century in African countries.

Similarly, counsellors' aptitudes in the use of science is delivered up in a world with restricted technological know-how as some can discover it hard to use it to have interaction and guide ecounselling except fantastic training.

Sussman (2002) lamented that glitzy technological know-how is at first very attractive and accompanied via exaggerated claims of being a "dragon slayer" or an answer to all that ails the instructional system; however, with terrible technical support, preservation and sustained effort through all stakeholders, it will become a state-of-the-art paperweight. However, overcoming these challenges can pave the away for the future prospect of our online world counselling in the twenty-first century.

\section{Prospect of Cyberspace Counselling in the twenty-first Century}

Many consumers will select to use our online world counselling due to motive such as:

\section{How Cyberspace Counselling Works}

Nowadays, it is very easy to talk online with one's counsellor. One can use a computer, tablet, iPhone, or smartphone anywhere one is, and one's counsellor will talk to one by an easy-touse, impervious service, like Skype or WhatsApp call. Sessions can be organized in enhance at a time to go well with the consumer and the counsellor. The events can additionally figure out whether or not they can use video name or simply speak instead.

\section{Counselling online and far-flung remedy is simply as effective}

Numerous research and NHS lookup have discovered our online world counselling and far off remedy to be simply as fantastic as traveling a counsellor or therapist face-to-face (Suleiman et al., 2019). Some consumers who have the time for face-to-face remedy even decide on our online world counselling due to the fact they locate it terrific as it offers them extra flexibility and comfort.

\section{Experience counselling from the remedy of your home}

There are all sorts of motives why humans pick our online world counselling, however many locate the ride is extra discreet and confidential. They sense that being capable of journey counselling from the relief of their personal domestic or workplace is much less embarrassing and lets them talk about private troubles extra overtly except emotions of guilt or shame. This is due to the reality that they can use a cell phone, laptop computer, or computing device pc and speak in a room the place they are aware of they will no longer be distracted.

\section{Conclusion}

Cyberspace counselling is developing rapidly. The net is no longer simply for chatting with pals and family anymore. Although the Internet has made verbal exchange simpler with emails, chat rooms, and immediate messaging services, many humans have additionally determined the World Wide Web to be useful in acquiring facts about intellectual health, inclusive 
of particular disorders, medication, and treatment. It was once solely dependent on time earlier than the availability of effortless conversation and intellectual fitness assets collectively to shape what is now regarded as our online world counselling. Cyberspace counselling actually does pose some special troubles and add some special probabilities for each the consumers and the therapists. As such, each counsellor and the purchaser who desires to have interaction in such offerings ought to be knowledgeable of each the advantages and boundaries of this fashion of therapeutic approach. Cyberspace counselling offers the customers possibility to communicate with a counsellor online, except having to meet them face-to-face.

\section{Recommendations}

Based on the above discussion, the following pointers are proffered thus:

1. The authorities must try to supply enabling surroundings (i.e. energy stability), and personal agency such as the net vendors and cellular telephone operators on their phase have to make bigger web accessibility and bandwidth that will assist the needs of the twenty first century.

2. Implementing new applied sciences in counselling requires that counsellors are efficiently skilled to advance new capabilities in the usage of the science and regularly in innovation. Counsellors will consequently want each time and education to increase these competencies, and directors have to permit for this when planning the timing and size of the implementation.

\section{REFERENCES}

Adewuyi, H. O. and Muraina, K. O. (2019). Crime Behavioural Tendency of School-Going Adolescents in Ibadan: Home Background, Self-Regulation and Parenting Processes as Predictors. Dev Sanskriti Interdisciplinary International Journal (DIIJ), (13), 119-128.

Augar, N., Raitman, R., \& Zhou, W. (2004). Teaching and Learning Online with Wikis. In R. Atkinson., C. McBeath., D. Jonas-Dwyer., \& R. Phillips (Eds.), Beyond the Comfort Zone: Proceedings of the 21st ASCILITE Conference (pp. 95-104). Perth, Australia.

Brown, T. (2008). M-learning in Africa: Doing the unthinkable and reaching the unreachable. In J. Voogt \& G. Knezek (Eds.), International Handbook of Information Technology inPrimary and Secondary Education. New York: Springer.

Cohen, G.E., and Kerr, B.A. (1998). "Computer-mediated counselling: An empirical study of a new mental health treatment". Computers in Human Services, 15 (4), 13-26.

Cook, J. \& Doyle, C. (2002). Working alliance in online therapy as compared to face to face therapy: Preliminary result. Cyberspace Psychology and Behaviour, 5, 95-105.

Mallen, M., Vogel, D., Rochlen, A., \& Day, S. (2005). Online counselling: Reviewing the literature from a counselling psychology framework. The counselling psychology, 33, 819-871.

Oladele, J. O. (2007). Guidance and counselling: A Functional Approch. (4 ${ }^{\text {th }}$ Edition). Lagos: johnsLad Publisher Ltd.

Oliver, B., \& Goerke, V. (2007). Australian Undergraduates' use and Ownership of Emerging Technologies: Implications and Opportunities for Creating Engaging Learning Experiences for the Net Generation. Australasian Journal of Educational Technology, 23(2), 171-186.

Salawu, A., A. \& Abdulkadir, O., R. (2011). Introduction to the Theory and Practice of Guidance and Counselling. Kwara: Integrity Publication.

Stofle, G.S. (2001). Choosing an online therapist.White Hat Communications.

Suleiman, Y., Muraina, K. O \& Suleiman, J. M. (2019). Improving Guidance and Counselling Services for Effective Service Delivery in Nigerian Secondary Schools: Implications for Stakeholders in Education. JOMSIGN: Journal of Multicultural Studies in Guidance and Counselling, Vol. 3 (1), 75-89.

Suler, J. (2000). "Psychotherapy in cyberspace: A 5 dimensional model of online and computer mediated psychotherapy".CyberPsychology\& Behavior, 3(2), 151-160. 
Sussman, R. J. (2002). Counselling over the internet: Benefit and challenges. Retrived from http://www.cybercounsel.uneg.edu 23/03/19

Thomas. L. G., \& Knezek, D. (2008). Information, Communications, and Educational Technology Standards for Students, Teachers, and School Leaders In J. Voogt \& G. Knezek (Eds.), International Handbook of Information Technology in Primary and Secondary Education. New York: Springer.

Wright, C. R. (2014). 5 Key Barriers to Educational Technology Adoption in the Developing World (Blog Post).Educational Technology Debate. Retrieved from http://efareport.wordpress.com. 23/03/19 